Corrigendum

\title{
Corrigendum to "More Than Needles: The Importance of Explanations and Self-Care Advice in Treating Primary Dysmenorrhea with Acupuncture"
}

\author{
Michael Armour $\mathbb{D}^{1},{ }^{1}$ Hannah G. Dahlen $\mathbb{D D}^{2}{ }^{2}$ and Caroline A. Smith $\mathbb{D}^{1}$ \\ ${ }^{1}$ The National Institute of Complementary Medicine, Western Sydney University, Locked Bag 1797, Penrith, NSW 2751, Australia \\ ${ }^{2}$ School of Nursing and Midwifery, Western Sydney University, Locked Bag 1797, Penrith, NSW 2751, Australia \\ Correspondence should be addressed to Michael Armour; m.armour@uws.edu.au \\ Received 31 January 2017; Accepted 19 March 2018; Published 30 April 2018 \\ Copyright (c) 2018 Michael Armour et al. This is an open access article distributed under the Creative Commons Attribution License, \\ which permits unrestricted use, distribution, and reproduction in any medium, provided the original work is properly cited.
}

In the article titled "More Than Needles: The Importance of Explanations and Self-Care Advice in Treating Primary Dysmenorrhea with Acupuncture" [1], the Competing Interests section should read as follows:

Michael Armour is a Director of Women's Health and Head of Acupuncture at The Body Workshop Ltd. in New Zealand, though he is not currently a practitioner there.

\section{References}

[1] M. Armour, H. G. Dahlen, and C. A. Smith, "More than needles: the importance of explanations and self-care advice in treating primary dysmenorrhea with acupuncture," EvidenceBased Complementary and Alternative Medicine, vol. 2016, Article ID 3467067, 11 pages, 2016. 


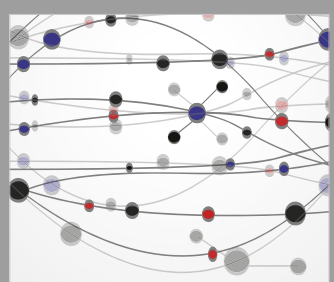

The Scientific World Journal
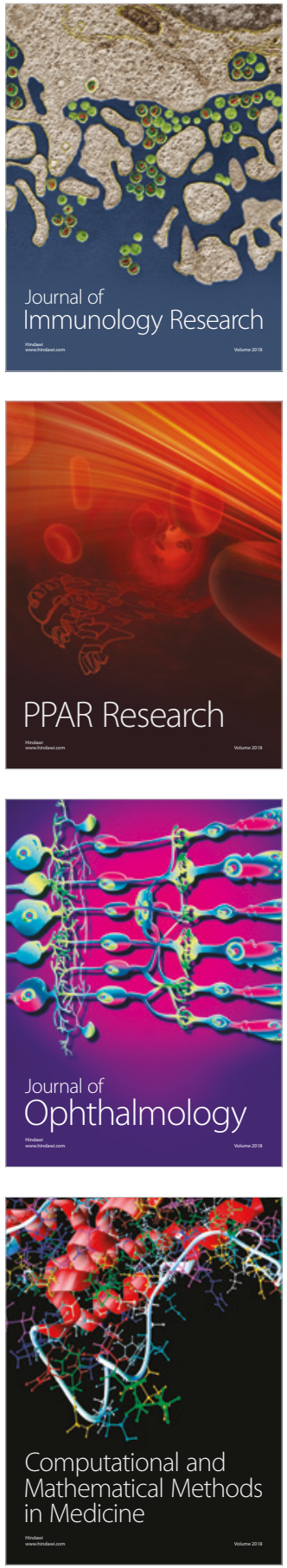

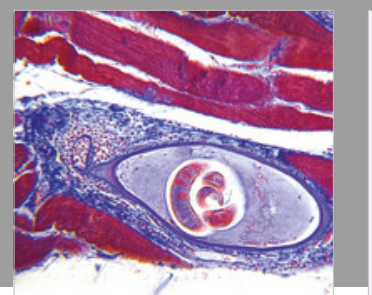

Gastroenterology Research and Practice

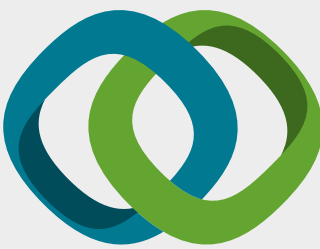

\section{Hindawi}

Submit your manuscripts at

www.hindawi.com
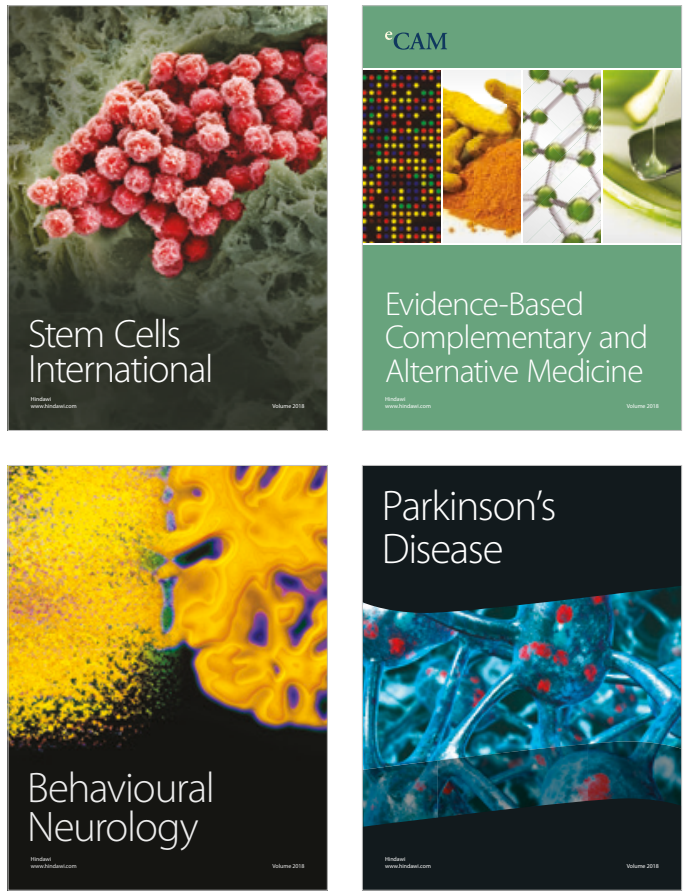

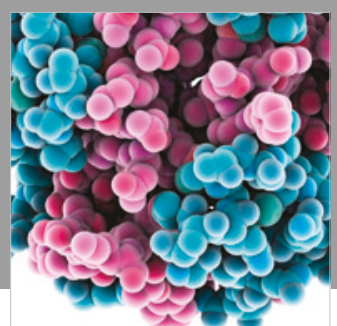

ournal of

Diabetes Research

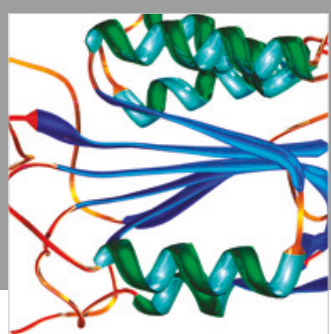

Disease Markers
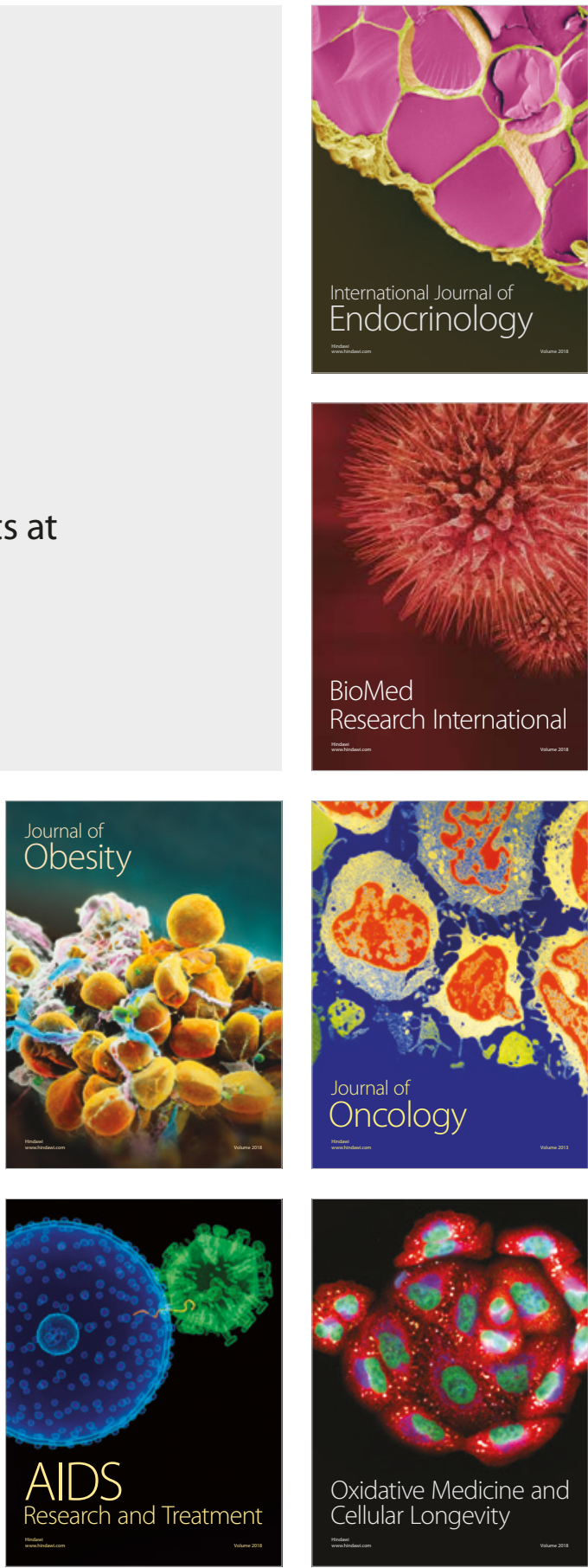